\title{
X-ray Microanalysis of Insulators in a Variable Pressure Environment
}

\author{
M. Toth*, J.P. Craven*, M.R. Phillips**, B.L. Thiel* and A.M. Donald* \\ * Polymers and Colloids Group, Cavendish Laboratory, University of Cambridge, Madingley Road, \\ Cambridge, CB3 OHE, U.K. \\ ** Microstructural Analysis Unit, University of Technology Sydney, Broadway, NSW 2007, \\ Australia
}

In a low vacuum environment, electric fields generated by ionized gas molecules and sub-surface trapped charge $(\mathrm{Q})$ can alter the primary electron landing energy $\left(\varepsilon^{\mathrm{DHL}}\right)$. Consequent artifacts in $\mathrm{x}$-ray microanalysis can be alleviated by working under conditions whereby the net electric field $(E)$ is dominated by the component produced by gaseous ions $\left(\underline{E}^{\mathrm{ION}}\right)$, and excess ions are rapidly removed via efficient ion neutralization routes. Such conditions can be attained over a wide of microscope operating parameters simply by employment of appropriate sample-electrode geometries.

In a variable pressure/environmental SEM, the electric field at each point $(x, y, z)$ in the space between the sample and the pole piece typically consists of three distinct components:

$$
\underline{E}(x, y, z)=\underline{E}^{E}(x, y, z)+\underline{E}^{Q}(x, y, z)+\underline{E}^{\text {iN }}(x, y, z)
$$

where $\underline{E}^{\mathrm{E}}$ is the field generated by a biased electrode (ie, the electron collector of a gaseous electron detector [1]) and $E^{Q}$ is the field produced by $Q$. If the specimen is an uncoated insulator, $\varepsilon^{\mathrm{DHL}}$ and the maximum bremsstrahlung $\mathrm{x}$-ray energy (the Duane-Hunt limit, $\mathrm{DHL}$ ) are given by:

$$
\varepsilon^{\mathrm{DHL}}=\mathrm{eV}^{\mathrm{A}}+\mathrm{e}\left(\Delta \mathrm{V}^{\mathrm{E}}+\Delta \mathrm{V}^{\mathrm{Q}}+\Delta \mathrm{V}^{\mathrm{ION}}\right)=\mathrm{eV}^{\mathrm{A}}+\mathrm{e} \Delta \mathrm{V}
$$

where $\mathrm{e}$ is the charge of an electron, $\mathrm{V}^{\mathrm{A}}$ is the primary electron accelerating voltage, and $\Delta \mathrm{V}$ is the net potential difference between the pole piece and the sample surface corresponding to $\underline{E}^{\mathrm{E}}, \underline{E}^{\mathrm{Q}}$ and $\underline{E}^{\mathrm{iON}}$. The sign of $\Delta \mathrm{V}^{\mathrm{O}}$ is determined by the net polarity of sub-surface charge, as in the case of high vacuum SEM $[2,3]$. However, in contrast to high vacuum $\mathrm{SEM}, \Delta \mathrm{V}^{\mathrm{ION}}$ can cause a significant increase in $\varepsilon^{\mathrm{DHL}}$, alter the overvoltage and compromise $\mathrm{x}$-ray quantification procedures. Such increases in $\varepsilon^{\mathrm{DHL}}$ are illustrated by the energy-dispersive $\mathrm{x}$-ray spectra shown in Fig. 1, acquired as a function of electrode bias $\left(\mathrm{V}^{\mathrm{E}}\right)$ and gas pressure $(\mathrm{P})$. The data clearly illustrate that $\varepsilon^{\mathrm{DHL}}$ scales with $\mathrm{V}^{\mathrm{E}}$ and $P$. This behavior is attributed to the influence of $V^{E}$ and $P$ on $E^{E}, E^{1 O N}$ and $E^{Q}$, and consequent effects of $\Delta V$ on $\varepsilon^{\text {DHL }}$ (see Eqn. 2). We will present a detailed model of $\varepsilon^{\mathrm{DHL}}$ behavior in a low vacuum environment, based on knowledge of the polarity of $\Delta \mathrm{V}^{\mathrm{Q}}$ and $\Delta \mathrm{V}^{\mathrm{ION}}$, obtained from simultaneous measurements of $\mathrm{x}$-ray spectra and Q-induced changes in the SE emission current.

From a practical viewpoint, it is desirable to eliminate the changes in $\varepsilon^{\mathrm{DHL}}$ caused by $\Delta \mathrm{V}$ without imposition of restrictions on operating parameters such as $\mathrm{V}^{\wedge}, \mathrm{V}^{\mathrm{k}}$, working distance and gas pressure. On the basis of the aforementioned model, this can be achieved if: (i) $\Delta \mathrm{V}^{\mathrm{F}}$ is minimized, (ii) $\Delta \mathrm{V}^{\mathrm{ION}}>$ $\Delta V^{Q}$, and (iii) excess ions are rapidly neutralized so that: $\Delta V^{10 N}+\Delta V^{Q} \approx 0$. In a low vacuum environment such conditions can be attained simply by employment of appropriate sample-electrode geometries in the specimen chamber. Equipotentials calculated for two-dimensional representations of two such geometries are shown in Fig. 2. The effectiveness of these geometries in reducing $\Delta \mathrm{V}$ induced $\varepsilon^{\mathrm{DHL}}$ shifts is demonstrated by the corresponding $\mathrm{x}$-ray spectra also shown in Fig. 2. These results will be explained using the abovementioned model. [4] 
References

[1] G.D. Danilatos, Adv. Electronics Electron Phys. 78 (1990) 1.

[2] J. Cazaux, J. Electr. Spect. Rel. Phen. 105 (1999) 155.

[3] L. Reimer, Scanning Electron Microscopy, Springer, Berlin, 1984.

[4] This work was sponsored by EPSRC (grant number GR/M90139) and FEI corporation.
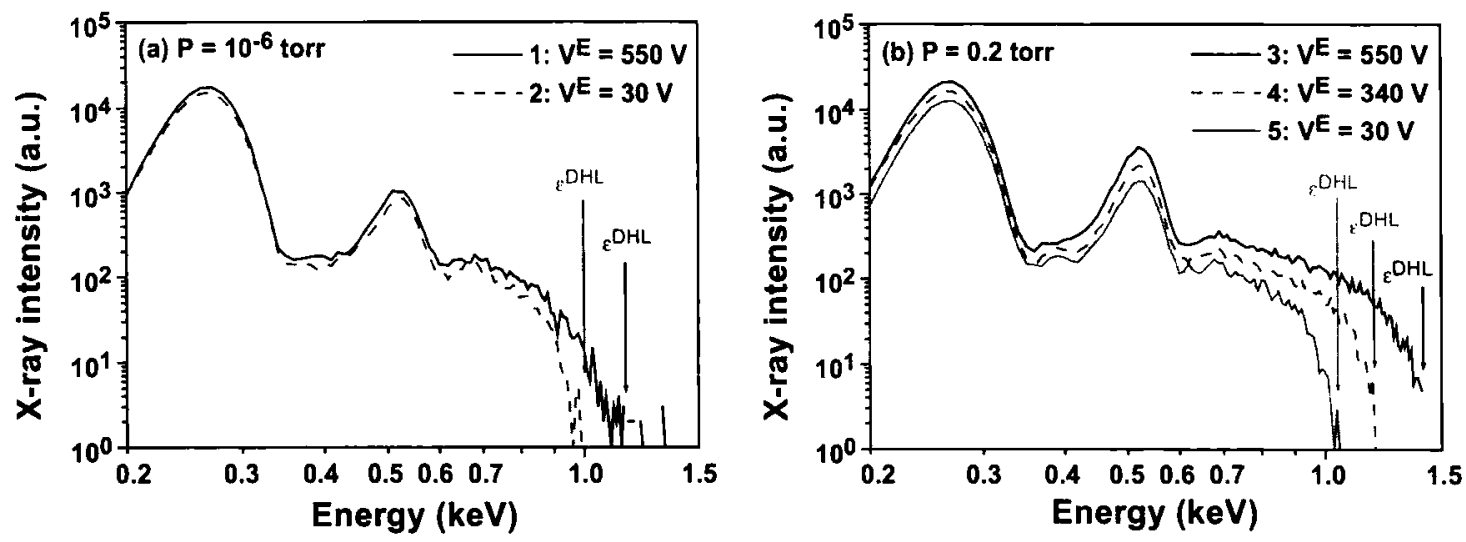

FIG. 1. Energy-dispersive x-ray spectra acquired consecutively from the same region of mica, in the order shown in the figures, as a function of electrode bias $\left(\mathrm{V}^{\mathrm{E}}\right)$ and water vapor pressure $(\mathrm{P})$ : (a) $\mathrm{P}=10^{-6}$ torr, (b) $\mathrm{P}=0.2$ torr. The data show that $\varepsilon^{\mathrm{DHL}}$ scales with $\mathrm{V}^{\mathrm{E}}$ and $\mathrm{P}\left[\mathrm{V}^{\mathrm{A}}=1 \mathrm{kV}\right.$, working distance $=10 \mathrm{~mm}$, electrode-sample separation $=4.5 \mathrm{~mm}$, horizontal field width $=130$ microns $]$.
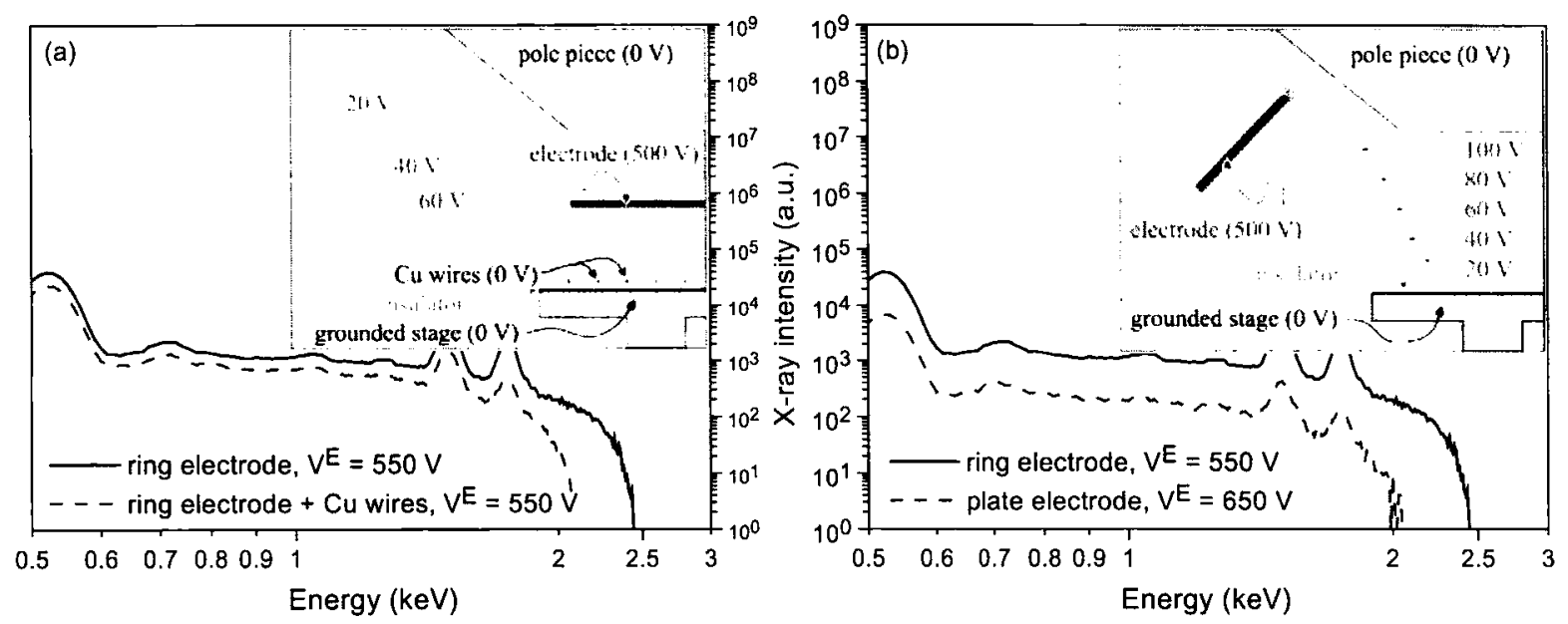

FIG. 2. X-ray spectra of mica showing differences between $\varepsilon^{\mathrm{DHL}}$ in data acquired when a ring electrode was placed $4.5 \mathrm{~mm}$ above the sample ("standard" geometry) and: (a) an array of grounded $\mathrm{Cu}$ wires was placed $0.55 \mathrm{~mm}$ above the specimen, or (b) the ring electrode was replaced with an off-axis plate electrode. [ $\mathrm{V}^{\mathrm{A}}=2 \mathrm{kV}, \mathrm{P}=0.5$ torr, working distance $=10 \mathrm{~mm}$, horizontal field width $=$ 130 microns]. The insets show the electric equipotentials (broken lines) calculated for simplified two-dimensional representations of the abovementioned geometries $\left[\mathrm{V}^{\mathrm{E}}=500 \mathrm{~V}\right]$. The spectra show that employment of these geometries serves to reduce Duane-Hunt shifts caused by gaseous ions. 


\section{Proceedings}

\section{MICROSCOPY AND MICROANALYSIS 2002}

Microscopy Society of America

$60^{\text {th }}$ Annual Meeting

Microscopy Society of Canada /

Société de Microscopie du Canada

$29^{\text {th }}$ Annual Meeting
Microbeam Analysis Society

$36^{\text {th }}$ Annual Meeting

International Metallographic Society

$35^{\text {th }}$ Annual Meeting

Québec City, Québec, Canada

August 5-8, 2002

Edited by

E. Voelkl

D. Piston

R. Gauvin

A. J. Lockley
G. W. Bailey
S. McKernan

Microscopy and Microanalysis, Volume 8, Supplement 2, 2002 


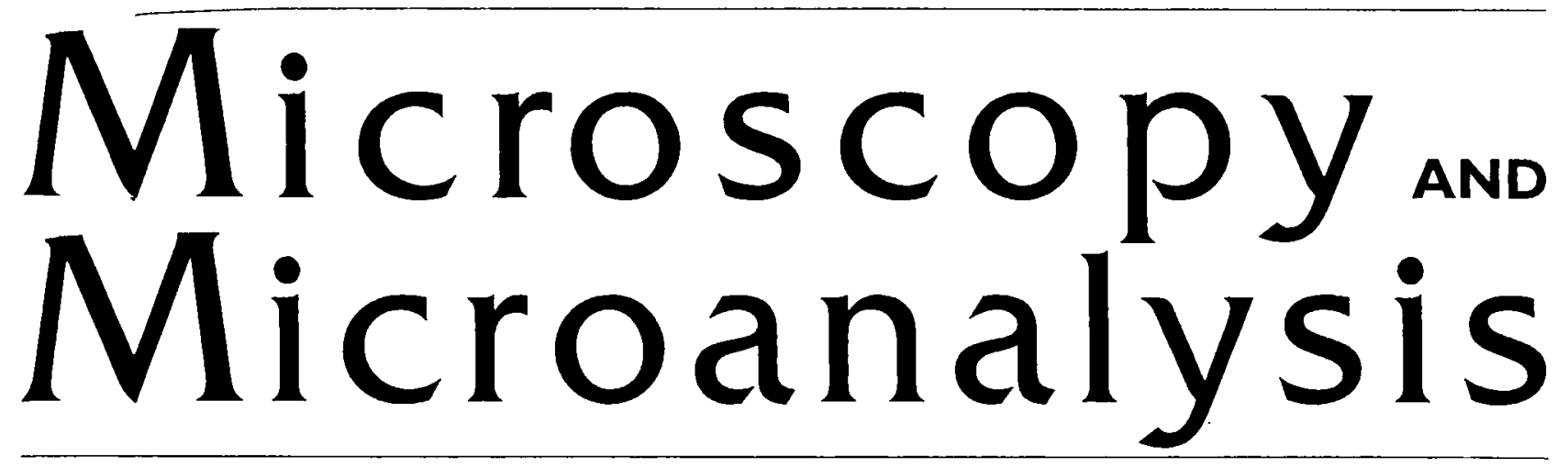

THE OFFICIAL JOURNAL OF

\author{
MICROSCOPY SOCIETY OF AMERICA \\ MICROBEAM ANALYSIS SOCIETY \\ MICROSCOPICAL SOCIETY OF CANADA / SOCIÉTÉ DE \\ MICROSCOPIE DU CANADA \\ MEXICAN MICROSCOPY SOCIETY \\ BRAZILIAN SOCIETY FOR MICROSCOPY AND MICROANALYSIS \\ VENEZUELAN SOCIETY OF ELECTRON MICROSCOPY \\ EUROPEAN MICROBEAM ANALYSIS SOCIETY
}

PUBLISHED IN AFFILIATION WITH

\author{
ROYAL MICROSCOPICAL SOCIETY \\ GERMAN SOCIETY FOR ELECTRON MICROSCOPY \\ BELGIAN SOCIETY FOR MICROSCOPY \\ MICROSCOPY SOCIETY OF SOUTHERN AFRICA
}

\section{Editor in Chief}

Editor, Microanalysis

Charles E. Lyman

Materials Science and Engineering

Lehigh University

5 East Packer Avenue

Bethlehem, Pennsylvania 18015-3195

Phone: (610) 758-4249

Fax: (610) 758-4244

e-mail:charles.lyman@lehigh.edu

Editor, Biological Applications

Ralph Albrecht

Department of Animal Sciences

University of Wisconsin-Madison

1675 Observatory Drive

Màdison, Wisconsin 53706-1581

Phone: (608) 263-3952

Fax: (608) 262-5157

e-mail: albrecht@ahabs.wisc.edu

Editor, Materials Applications

C. Barry Carter

Chemical Engineering and Materials Science

151 Amundson Hall

University of Minnesota

Minneapolis, Minnesota 55455-0132

Phone: (612) 625-8805

Pare: (612) 626-7246

ezaali: sarter@cems,umn.edu
Editor, Materials Applications

Vinayak P. Dravid

Materials Science and Engineering

Northwestern University

2225 N. Campus Drive, Room 3013A

Evanston, Illinois 60208-3105

Phone: (847) 467-1363

Fax: (847) 491-7820

e-mail: v-dravid@nwu.edu

Editor, Light and Scanning Probe Microscopies

Brian Herman

Cellular and Structural Biology

University of Texas at San Antonio

7703 Floyd Curl Drive

San Antonio, Texas 78284-7762

Phone: (210) 567-3800

Fax: (210) 567-3803

e-mail: hermanb@uthscsa.edu

Editor, Biological Applications

Heide Schatten

Veterinary Pathobiology

University of Missouri-Columbia

1600 E. Rollins Street

Columbia, Missouri 65211-5030

Phone: (573) 882-2396

Fax: (573) 884-5414

e-mail: schattenh@missouri.edu
News and Commentary Editor Book Review Editor

JoAn Hudson

Institute of Neuroscience

University of Oregon

222 Huestis Hall

Eugene, OR 97403-1254

Phone: (541) 346-4508

Fax: (541) 346-4548

e-mail: hudson@uoneuro.uoregon.edu

Special Section Editor

James N. Turner

Phone: (518) 474-2811

Fax: (518) 474-8590

e-mail: turner@wadsworth.org

\section{Expo Editor}

William T. Gunning III

Phone: (419) 383-5256

Fax: (419) 383-3066

e-mail:wgunning@mco.edu

\section{Proceedings Editor}

Stuart McKernan

Phone: (612) 624-6009

Fax: (612) 625-5368

e-mail: stuartm@tc.umn.edu 


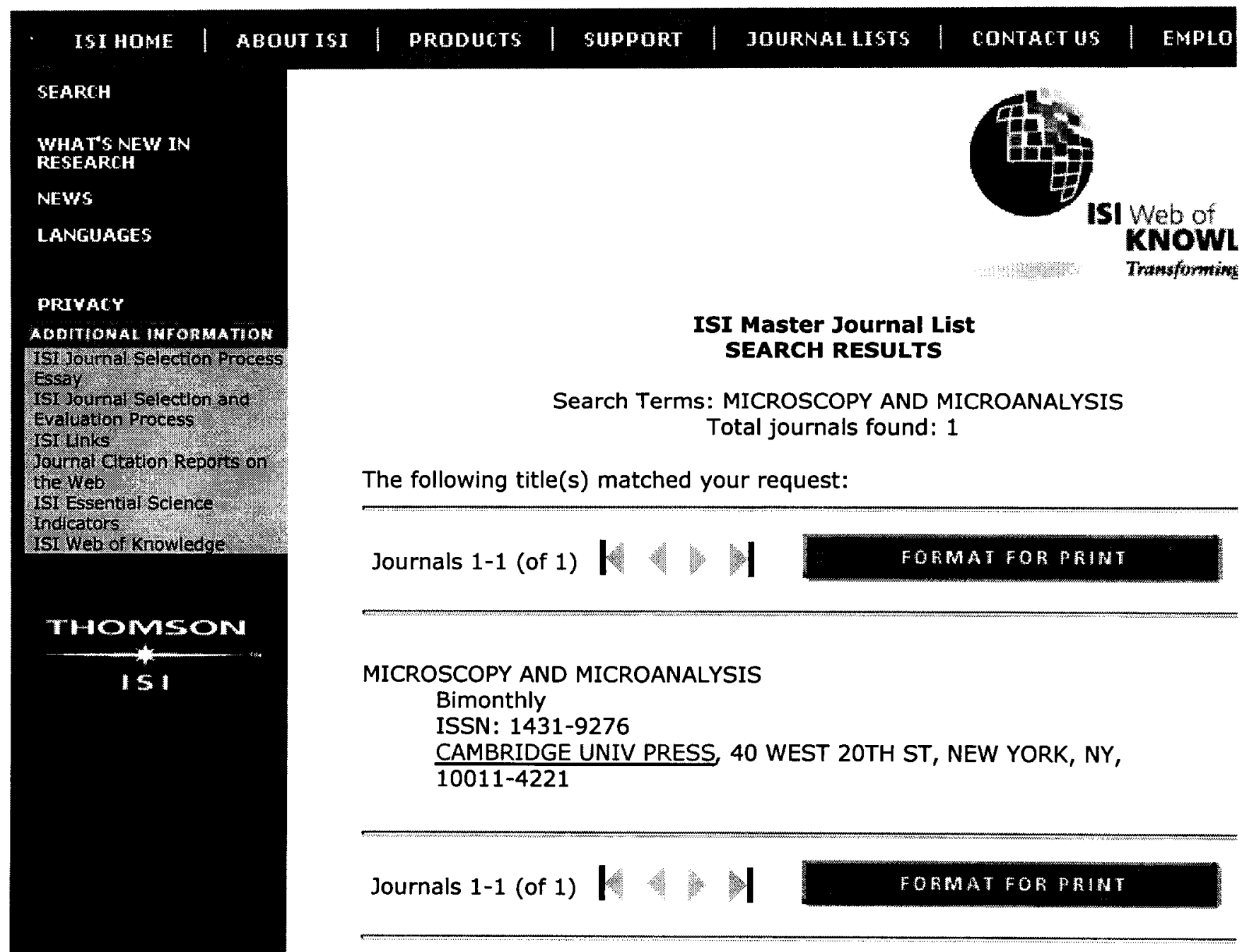


Cammoncir | Joumals

Home > Journals > Search > Results > Microscopy and Microanalysis

\section{Microscopy and Microanalysis}

\section{Edited by}

\section{Charles E. Lyman}

Lehigh University, USA
- Editorial Board
- Pricing
- Links

\author{
- Instructions for Contributors \\ - Full Text Online (purchase or subscribe) \\ - Advertising Rates
}

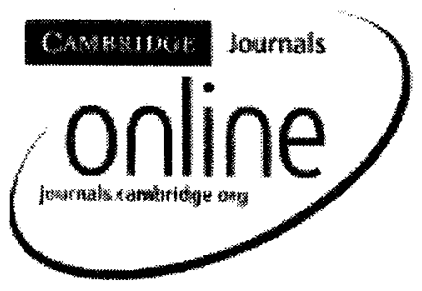

\section{Current Issue}

Volume 9-9, 2003

February, April, June, August, October, December

Print ISSN: 1431-9276

Online ISSN: $1435-8115$

\section{Published for the Microscopy Society of America}

To view a sample of this journal click here

Microscopy and Microanalysis, a peer-reviewed bimonthly, publishes original research papers in the fields of microscopy, imaging, and compositional analysis. This distinguished international forum is intended for microscopists in both materials science and biology. The journal provides significant articles that describe new as well as existing techniques and instrumentation, and the applications of these to the imaging and analysis of microstructure. Microscopy and Microanalysis also includes brief technical communications, review articles, letters to the editor, news, and commentary of interest. 